\title{
MOLGENIS catalogue
}

\author{
Morris Swertz ${ }^{1 *}$, David van Enckevort ${ }^{1}$, Chao Pang ${ }^{1,2}$ \\ From 1st Clinical Research Informatics (CRI) Solutions Day \\ Duesseldorf, Germany. 26-27 May 2014
}

\section{Characterisation}

Tool, biobanking, meta-data, data, miabis, open source.

\section{Description}

MOLGENIS/catalogue is a generic toolbox for building biobank and study catalogues and is used in BBMRI-NL, EU-BioSHaRE, EU-BioMedBridges, LifeLines, CTMM/
TraIT, Durrer Center, PALGA NL pathology network. The catalogue can host four levels of information:

1) Biobank/study descriptions using custom or MIABIS standard of BBMRI-ERIC format;

2) Data schema/data dictionary of data elements;

3) Aggregate data/sample availability counts and;

4) Individual level data ready for analysis.

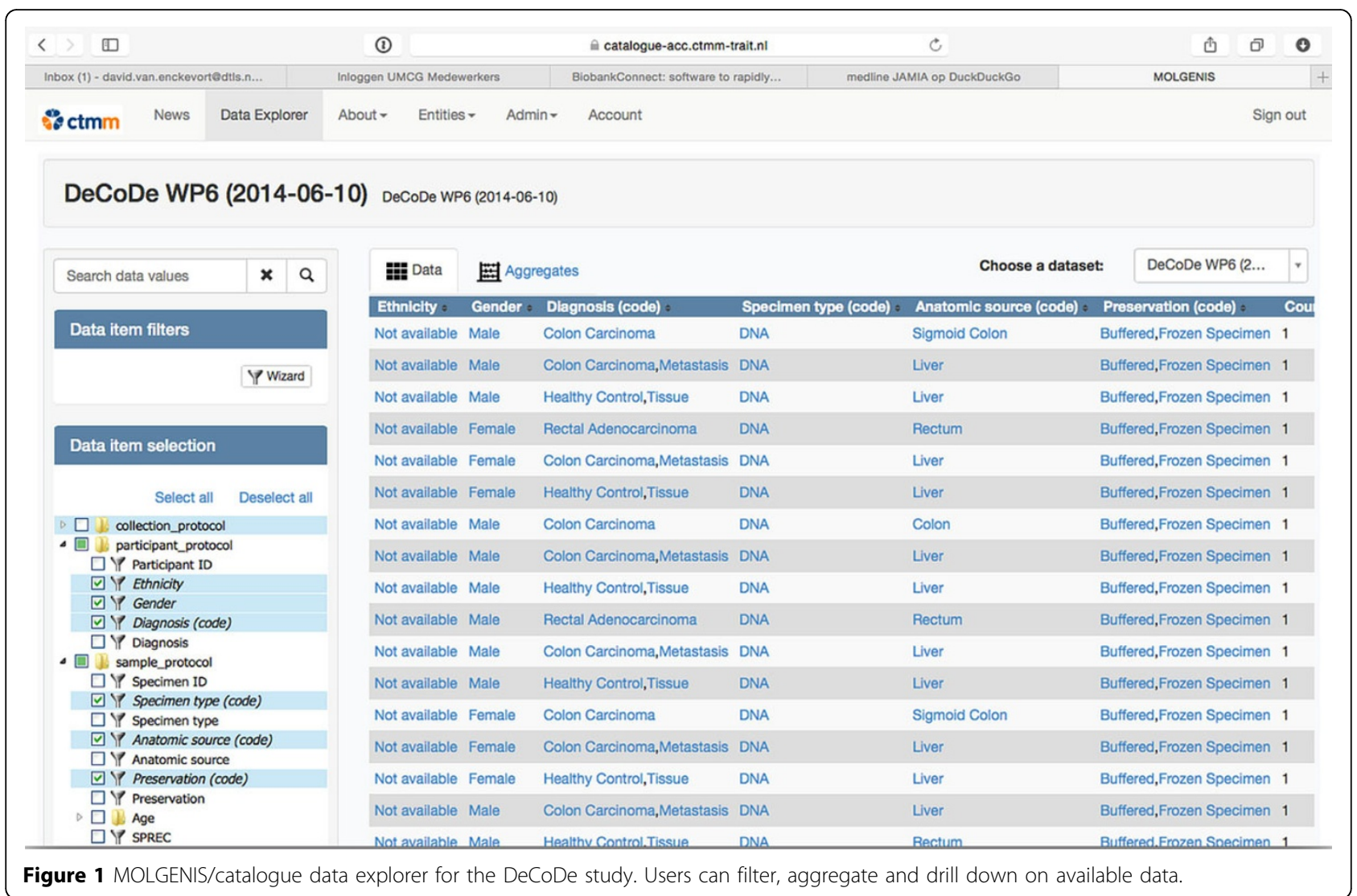

\footnotetext{
* Correspondence: m.a.swertz@rug.nl

'Department of Genetics, University Medical Center Groningen, University of Groningen, 9700RB Groningen, the Netherlands

Full list of author information is available at the end of the article
}

C Biomed Central

(c) 2015 Swertz et al; licensee BioMed Central Ltd. This is an Open Access article distributed under the terms of the Creative Commons Attribution License (http://creativecommons.org/licenses/by/4.0), which permits unrestricted use, distribution, and reproduction in any medium, provided the original work is properly cited. The Creative Commons Public Domain Dedication waiver (http:// creativecommons.org/publicdomain/zero/1.0/) applies to the data made available in this article, unless otherwise stated. 
Increasingly bigger datasets are required for epidemiological and genetic analysis; hence it has become important to enable pooling of data from multiple biobanks. Therefore, the catalogue also comes with BiobankConnect, a tool to rapidly match data elements across studies and biobanks based on lexical matching and ontologies [1]. MOLGENIS/catalogue is build on the open source MOLGENIS platform [2] and offers pre-build components that allow users to upload data in a simple Excel format and supports any data model through a meta-data definition in the Excel file; to visualize the data in aggregated or tabular form; to share securely data through a comprehensive security model and to integrate data from different domains (Figure 1).

\section{Status of development}

Stable/production ready; version 1.2.0.

\section{Users}

10 known installations.

\section{Links}

http://github.com/molgenis/molgenis, http://www.molgenis. org, https://www.dropbox.com/s/bez1r4lq5q69o9e/Swertz\% 20ECRIN\%20Dussseldorf\%20catalogue\%202014_05_26. pptx.pdf.pdf

\section{Authors' details}

Department of Genetics, University Medical Center Groningen, University of Groningen, 9700RB Groningen, the Netherlands. ${ }^{2}$ Department of

Epidemiology, University of Groningen, University Medical Center Groningen, Groningen, the Netherlands.

Published: 22 May 2015

\section{References}

1. Pang C, Hendriksen D, Dijkstra M, van der Velde K, Kuiper J, Hillege $H$, Swertz MA: BiobankConnect: software to rapidly connect data elements for pooled analysis across biobanks using ontological and lexical indexing. J Am Med Inform Assoc 2014, epub ahead of print. doi: 10.1136/ amiajnl-2013-002577.

2. Swertz MA, Dijkstra M, Adamusiak T, van der Velde JK, Kanterakis A, Roos ET, et al: The MOLGENIS toolkit: rapid prototyping of biosoftware at the push of a button. BMC Bioinformatics 2010, 11(Suppl 12):S12

doi:10.1186/2043-9113-5-S1-S8

Cite this article as: Swertz et al:: MOLGENIS catalogue. Journal of Clinical Bioinformatics 2015 5(Suppl 1):S8.

\section{Submit your next manuscript to BioMed Central} and take full advantage of:

- Convenient online submission

- Thorough peer review

- No space constraints or color figure charges

- Immediate publication on acceptance

- Inclusion in PubMed, CAS, Scopus and Google Scholar

- Research which is freely available for redistribution

Submit your manuscript at www.biomedcentral.com/submit 